\title{
WEBSURVEYS COMO MÉTODO DE PESQUISA ${ }^{1}$
}

\section{WEBSURVEYS COMO UN MÉTODO DE INVESTIGACIÓN}

\author{
Consuelo Chaves Joncew - consuelo.chavesbh@gmail.com \\ Doutora em Ciências da Informação pela Universidade Federal de Minas \\ Gerais(UFMG). Gerente na Caixa Econômica Federal. \\ Beatriz Valadares Cendon - bcendon@gmail.com \\ Doutora em Ciência da Informação pela University of Texas at Austin. \\ Professora da Universidade Federal de Minas Gerais (UFMG). \\ Nádia Ameno - nadiaameno@gmail.com \\ Doutoranda em Ciência da Informação pela Universidade Federal de \\ Minas Gerais (UFMG).
}

\section{RESUMO}

Introdução: $O$ presente artigo relata a análise de 531 comentários extraídos de 564 mensagens recebidas de respondentes a um questionário de pesquisa de grande porte que levantou dados sobre o uso do Portal de Periódicos da Capes, por 14.763 docentes de 17 universidades federais brasileiras.

Objetivo: O estudo procura trazer mais luz sobre os desafios e dificuldades do websurvey através da análise das mensagens recebidas dos respondentes, dos fatores que as motivam, das reações dos respondentes ao websurvey e da comparação dos resultados com outros estudos semelhantes encontrados na literatura.

Metodologia: Empregou-se uma metodologia principalmente quantitativa, com a coleta de alguns dados qualitativos. Os dados são provenientes de mensagens enviadas pelos usuários aos pesquisadores e também de alguns campos abertos dos questionários do websurvey.

Resultados: Os comentários analisados corroboraram para justificar alguns desafios que os pesquisadores enfrentam, dentre eles: planejar estrutura de suporte tecnológica eficiente; manter cadastro atualizado do público alvo, do qual se possa extrair amostra representativa, e zelar continuamente para a comunicação simples e direta, que possibilite o perfeito entendimento do respondente.

\footnotetext{
${ }^{1}$ Este trabalho recebeu financiamento do CNPq.
} 
Conclusões: A metodologia da websurvey ainda se encontra na infância, com vários desafios a serem assumidos, em investigações instigantes.

Palavras-chave: Survey. Bibliotecas digitais de periódicos. Estudos de usuário.

\section{INTRODUÇÃO}

Surveys são investigações que colhem dados de amostra representativa de uma população específica, que são descritos e analiticamente explicados. Pretendese que os resultados sejam generalizáveis ao universo dessa população, evitandose realizar o censo, ou seja, ouvir todos os indivíduos, o que é impossível, por questão de custo e de tempo (BABBIE, 2005). Embora o conceito de survey não tenha sofrido grandes alterações ao longo dos anos, ele absorveu o impacto positivo das tecnologias de informação e comunicação. Os chamados websurveys alteraram gradualmente o alcance do número de respondentes, a velocidade do trabalho, as técnicas de abordagens e os custos das pesquisas. Entre outras implicações, citamse, ainda, a automatização, a simplificação da coleta e tabulação dos dados e a melhoria da apresentação dos dados.

Entretanto, o websurvey ainda não é entendido como forma de maximizar benefícios e minimizar problemas, pois trouxe novos desafios e dificuldades. Para os interessados no assunto, a literatura mostra que há poucos estudos sobre a condução de websurveys. Tal fato explica-se, em parte, porque muitos intelectuais demoraram a assumir o fenômeno da web como interesse acadêmico, pois foram amadores os que começaram a utilizá-la, sem planejamento. Tal fato gerou desconfiança entre pesquisadores profissionais (DILLMAN; BOWKER, 2001). Hoje, com maior conhecimento e interação com a rede, estudiosos começam a se dedicar ao tema.

Visando trazer mais luz sobre os desafios e dificuldades do websurvey, 0 corrente artigo relata a análise de 531 comentários contidos em 564 mensagens ${ }^{2}$ recebidas de respondentes a um questionário de pesquisa de grande porte que levantou dados sobre o uso do Portal de Periódicos da Capes, por 14.763 docentes de 17 universidades federais brasileiras. A análise procura explicar e documentar 0

\footnotetext{
${ }^{2}$ Os 564 comentários originaram-se de 531 pessoas. Algumas registraram vários comentários. Em vários casos, reuniram-se os comentários de uma mesma pessoa em um só registro.
} 
tipo e quantidade de mensagens recebidas, os fatores que as motivam e as reações dos respondentes comparando os resultados com os relatos existentes na literatura.

\section{WEBSURVEYS}

Em alguns aspectos, os métodos dos websurveys assemelham-se aos utilizados na coleta de dados das pesquisas quantitativas. Em outros, diferenciam-se por características e desafios peculiares (COUPER, 2001).

Primeiramente, a pesquisa desenvolvida na web dispensa a intermediação do entrevistador, que, tradicionalmente treinado, garantia sigilo sobre identidade, colhia pessoalmente os dados do respondente, motivando-o, incentivando-o a completar corretamente o preenchimento dos questionários, clareando eventuais dúvidas. As pesquisas na web são administradas pelos próprios respondentes, sem intermediação. A fonte de inspiração e elucidação de dúvidas foi transferida para o instrumento de pesquisa, o questionário ou script, que deve conduzi-los ao término da pesquisa, de forma completa, ótima e confiável. A comunicação entre respondente e o pesquisador acontece através do questionário. Tal fato maximiza a importância do planejamento e desenho do instrumento de coleta de dados, foco de preocupação de vários estudiosos da área.

Em segundo lugar, websurveys são feitos através de computadores. Ao contrário de pesquisas feitas por envio de e-mails, instrumentos estáticos, a Web viabiliza poderosas soluções informatizadas de assistência ao respondente. Através da linguagem de programação, os métodos incluem a automação dos skips, desvios, a edição de check boxes explicativos, recursos áudio visuais, a inclusão de comentários em questões abertas e várias outras possibilidades. A "forma" ganha relevância e interfere sobre o "conteúdo" das questões. Embora nem todos os recursos sejam usados padronizadamente, eles estão à disposição, como: efeitos de animação, interatividade, links com sites diversos, cores, multimídia, fotos, gráficos, muito dispendiosos nas pesquisas tradicionais.

Nos dois aspectos apresentados, websurveys assemelham-se aos métodos conhecidos como CASI (computer assisted self-interviewing). No entanto, por mais que o pesquisador planeje e teste o script da pesquisa, nas websurveys, os entrevistados respondem à investigação em formas, ambientes e tempos variados, com softwares e equipamentos diferentes que podem alterar significativamente 0 
layout original do questionário. A combinação dos elementos citados tornou a web um meio único para apresentação de perguntas e coleta de respostas. A grande oferta de recursos a explorar e a liberdade de expansão tem preço. A inclusão de estímulos gera efeitos inesperados e adversos, que podem levar a possíveis erros de mensuração.

Smith (1997), Redline et al. (2001), Couper (2001), Hansen (2000), Burgess (2001) e Bosnjac e Tutten (2001) Dilmann et al. (1998) investigaram como os efeitos disponibilizados alteram a compreensão dos entrevistados. Problemas na navegação demonstram o quanto um script mal elaborado pode afetar as respostas dos respondentes. Muitos destes problemas surgem quando se foca mais a programação técnica do que o conteúdo em si do questionário. Para Burgess (2001), o trabalho na web deve ser gerido por especialista em pesquisa, que vai explorar a variedade de opções que o meio proporciona, dentre elas: desenho e construção dos scripts; identificação e manutenção, envio dos questionários, tabulação e análise dos dados.

A internet e o contínuo avanço de soluções computadorizadas em softwares amigáveis e interativos, como os hotsites ${ }^{3}$, trouxeram alterações significativas ao processo de pesquisa em todas suas etapas. Denominações novas surgiram, como websurvey ${ }^{4}$, que, na verdade, preservaram o conceito de pesquisa quantitativa, porém, com a peculiaridade de ser desenvolvida com recursos da web. Opondo-se às pesquisas tradicionais, conduzidas pessoalmente pelo entrevistador, por telefone ou cartas, a websurvey evidencia nova e importante variável: a subjetividade do respondente, que impacta consideravelmente o planejamento do desenho da pesquisa, principalmente a elaboração dos instrumentos de coletas de dados.

\subsection{Planejamento e Design}

Pesquisas são caras e demandam tempo considerável para serem conduzidas. É importante que se promovam análises extensivas, que se preparem

\footnotetext{
${ }^{3}$ Pequeno sítio, planejado de acordo com as diretrizes de arquitetura de um website, para apresentar uma ação pontual de comunicação. marketing ou colher dados em uma pesquisa. Seu tempo de vida útil limita-se ao alcance do objetivo pretendido. O planejamento contempla apelo visual maior, focado em um público específico, traduzindo a expectativa deste alvo.

${ }^{4}$ Bonnel e Le Nir (1998) excluíram do conceito surveys feitos com envio de questionários por email. A distinção da websurvey seria o link ou o hotsite. Outros autores defendem que qualquer pesquisa pode ser potencializada pela web, que introduz a interatividade com o respondente como vantagem e nova variável, viabilizando efeitos áudio visuais e tabulação em tempo real (ALSNIH, 2005).
} 
planos detalhados e bem testados antes de começá-las. O projeto obedece a alguns princípios básicos, compreendendo etapas previstas pelo rigor científico, como: delimitação do problema, exposição de objetivos gerais e específicos, revisão de literatura sobre os temas da problemática, a delimitação do universo populacional, definição do plano amostral, a construção de hipóteses, explicitação de variáveis dependentes e independentes, escolha da metodologia, elaboração e pré-testes de instrumentos para coleta de dados, tabulação, análise e a redação de relatório de apresentação de resultados. Ou seja, a essência do planejamento continua a mesma, com pequenas alterações aqui e ali. Deve incluir atores como comunicadores, psicólogos e designers e requer a previsão de considerável infraestrutura tecnologia de suporte. O servidor deve estar sempre ligado, possibilitando acesso remoto dia e noite durante todo o período de coleta de dados.

\subsection{Amostragem}

O uso da Web em pesquisas cresce concomitante ao acesso da população à rede, dividida em diferentes nichos de pessoas, com diferenciadas habilidades, níveis de conhecimento e formas de interação com as tecnologias. Recomenda-se o uso da websurvey quando se conhece a população específica da pesquisa, com grau conhecido de afinidade, cujo banco de dados pode ser controlado, obtendo-se plano amostral representativo (IRAGUEN; ORTÚZAR, 2004; STOPHER; COLLINS; BULLOCK, 2004; ARENTZE; HOFMAN; TIMMERMANS, 2004). Vários softwares estatísticos possibilitam cálculos automáticos de tamanho de amostras, nível de confiança e margem de erro. Tradicionalmente, os surveys eram planejados para obterem $95,5 \%$ de nível de confiança e $5 \%$ margem de erro. O plano amostral previa, em populações acima de cerca de 70 mil indivíduos, 400 casos válidos. Com a web, o número de respostas ultrapassa expectativas, sendo comum o alcance de milhares de respondentes.

\subsection{Questionário}

A primeira recomendação é incluir os dados de identificação constantes no banco de dados (nome, idade, data de nascimento profissão, local de trabalho, endereço e telefone) no cabeçalho da pesquisa, sem necessidade de preenchimento pelo respondente. 
Antes do envio, vários autores aconselham que uma carta de apresentação, clara e concisa, seja remetida aos respondentes, explicando os objetivos da investigação, a metodologia, as etapas e a importância do preenchimento completo do questionário a ser enviado. É útil criar um link tipo "fale conosco" e com o site dos pesquisadores, para casos de os respondentes demandarem maiores detalhes, ajuda ou mais informações de esclarecimento.

O pesquisador deve informar sobre o envio e confirmação de recebimento do questionário, assim como agradecer a participação do respondente, que deve receber instruções sobre o padrão do questionário, mecanismos de desvios e orientações de navegação. Vários autores recomendam o envio de lembretes ao respondente, até que ele complete o questionário.

Tomadas as precauções genéricas, parte-se para a elaboração do questionário, que tem recebido várias sugestões na literatura.

A preocupação com a comunicação clara e não ambígua, com vistas a conseguir as respostas desejadas, explicita-se em inúmeros artigos que versam sobre instrumentos de coleta dados na web. Burgess (2001), Zanutto (2001), Dillman, Tortora e Bowker $(1998)^{5}$ sugerem dicas como: fazer exaustivos pré-testes, testando compreensão, navegação e eficiência dos desvios; orientar sobre os desvios, se preciso, a cada pergunta; planejar o questionário sem excesso de estímulos visuais, usando de simplicidade e clareza de linguagem; exibir uma pergunta por tela; não impor desvios na primeira pergunta; usar formato similar àqueles em questionário de papel, observando que as pessoas lêem da esquerda para a direita e de cima para baixo; controlar desvios para evitar erros de preenchimento; introduzir texto objetivo e simples, explicando cada pergunta e o se

5 Dillman, Tortora, e Bowker (1998) defendem a padronização do questionário. Como em pesquisas feitas em formulários de papel, o padrão facilita a compreensão e contribui para manter o interesse do respondente na pesquisa. Sugerem três critérios (padrão, clareza e concisão) para o desenho e 11 princípios para a elaboração de questionários na web: (1) usar tela de boas vindas para motivar e facilitar as respostas, mostrando como respondentes mudam de página; (2) ter a primeira questão inteira na primeira tela, assegurando facilidade de compreensão. A primeira questão não deve conter filtros, desvios ou caixas de diálogo'; (3) usar formato convencional, similar a formulários em papel,evitando falta de espaço, excesso de artifícios visuais. Excesso de brilho, tipos de fontes e espaços podem confundir. Formatos tradicionais tornam a navegação mais amigável; (4) limitar tamanho dos textos das perguntas. (5) exibir instruções, se necessárias, como opções de correção, desvios e limpar questões abertas. (6) instruções devem surgir quando necessárias, nunca no início da tela; (7) não obrigar respondente a registrar resposta para mudar de tela; (8) usar barra de rolagem que permita livre movimentação do respondente, a menos que um desvio seja imprescindível; (9) certificar que todas as respostas estejam em uma tela, usando espaço à parte para ajuda; (10) visualizar graficamente ao respondente o progresso da pesquisa; (11) ter cautela na estruturação de categorias de respostas que dificultem mensuração. 
quer com ela, sempre que necessário ${ }^{6}$, disponibilizando botões explicativos; usar layout limpo e atraente (nada de recursos como palavras e símbolos piscando); evitar perguntas dúbias. Sugerem, também, dividir o questionário em seções; limitar tamanho da pergunta e respostas em uma tela; limitar tempo de resposta do questionário em 20 minutos; disponibilizar botões para corrigir respostas; facilitar navegação para o usuário; mostrar ao respondente o progresso da pesquisa graficamente na tela para ele se contextualizar; oferecer privacidade; usar poucos tipos e tamanhos legíveis de fontes, evitando a poluição visual e proporcionando leitura amigável.

O layout de cada pergunta deve ser consistente e padronizado para atrair o respondente. As questões não devem ser longas. Não é recomendável colocar excessos de informação em cada página. Os botões de ajuda, também concisos e claros, serão acionados apenas se necessário, não comprometendo o layout da página. O questionário deve começar com perguntas mais interessantes e a sequência delas deve ser lógica, para que a leitura flua com simplicidade. O número de opções de respostas deve ser o menor possível. É bom providenciar várias versões, casos os respondentes demandem diferenciações, como: idioma, linguagem a deficientes etc.

\subsection{Os Respondentes dos Websurveys}

Inúmeros artigos versando sobre "respondentes e não respondentes" ilustram a preocupação com a comunicação com o público da pesquisa. Vários autores procuram entender porque algumas pessoas aceitam o convite para a pesquisa e outras não. O interesse no feedback, seja negativo ou positivo, desperta a curiosidade de estudiosos. Além do uso de estímulos e prêmios para atrair o interesse dos respondentes, destacam variáveis que interferem na receptividade deles, como nível de educação; familiaridade e interação com a internet ou suspeitas de spam por parte de quem recebe o convite para a pesquisa.

Bosnjak e Tuten (2001) classificam os questionários em três categorias: respostas completas, item não respondido (quando um item ou outro fica sem resposta) ou unidade não respondida, quando não há preenchimento total, por inacessibilidade, incapacidade ou falta de vontade do suposto respondente. Já

${ }^{6}$ Stopher, Collins e Bullock (2004) recomendam limitar em seis o número de lembretes e caixas explicativas nas pesquisas feitas por telefone. Mas autores sugerem que, na web não haja limitação. 
Dillman et al (1999) classificam os respondentes em dois tipos: "otimizadores", que dedicam total atenção à pesquisa, e "satisfatórios", que respondem com pouco esforço e tempo.

Bosnjak and Tuten (2001) identificaram sete tipos de respondentes em websurveys: 1) "Respostas completas" (participantes lêem e respondem todas as questões); 2) "Unidades não respondidas" (nenhuma questão é respondida, por recusa oriunda por qualquer motivo); 3) "Respostas puladas"; 4) "Perdidas" (lurkers), quando o respondente se perde no preenchimento; 5) "Perdidas puladas"; 6) "Item não respondido" (uma questão não é respondida) e 7) "Itens não respondidos pulados". Análises confirmam a existência dos sete tipos e sua compreensão colabora para minimizar os problemas.

Petty and Cacioppo $(1984,1986)$ e Chaiken $(1980,1987)$ destacam a importância da motivação, oportunismo, disponibilidade e habilidade no processo de se obterem respostas completas. Pessoas podem se perder por dificuldades técnicas, falta de habilidade, restrições de tempo, motivação, proteção provocada por um desvio do próprio questionário ou falta de experiência. Alguns autores trabalham com as hipóteses de que os respondentes completos tenham melhor nível de instrução ou de condição socioeconômica, que os diferencia em personalidade e interesse de participação; ou de que alguns respondentes podem simplesmente se cansar, enquanto outros são mais dispostos.

A classificação aponta para três direções investigativas: 1) procurar técnicas diferenciais que levem à efetividade das respostas; 2) entender o efeito dos ruídos e mecanismos de não respostas para promover técnicas corretivas, já que atitudes desconhecidas dos não respondentes podem provocar erros analíticos; e 3) compreender o contexto psicológico do entrevistado, para saber por que e como algumas pessoas aceitam participar e outras recusam.

\subsection{Desafios dos Surveys}

Segundo Groves, Cialdini e Couper (1992), Dillman e Bowker (2001), e Couper (2001), entre as limitações do websurvey, destacamos quatro: erro de cobertura (1), erro de amostragem (2), aumento de não respondentes (3) por razões diferenciadas (SCHAEFER; DILLMAN, 1998) e erros de mensuração (4).

Erros de cobertura (1) acontecem porque a população que acessa a internet é heterogênea e representa uma minoria. $O$ acesso à rede não pode ser considerado 
como indicador único que permita considerar o internauta como individuo pertencente à população de todo websurvey. As habilidades, nível de conhecimento e contexto cultural do usuário diferem. Bradley (1999) sustenta que ainda não há formas de se controlarem estes problemas.

A falta de cautela com o estudo da população traz implicações ao plano amostral (2), dificultado quando a base de dados não é pré-definida e controlada, como nas pesquisas tradicionais, que permitem verificações individualizadas, a não ser em casos como usuários de um portal específico de uma universidade ou pessoas que trabalham em uma mesma organização. Alguns especialistas validam websurveys apenas em casos de comunidade de indivíduos com afinidades e características homogêneas. Buscando administrar esse problema, diversas organizações investem na atualização dos cadastros de clientes na web, através de incentivos à autenticação consentida, usando artifícios como sorteio de brindes e outras iniciativas.

O crescimento do número de pessoas que acessam a Internet não é acompanhado pelo aumento da habilidade delas em lidarem com o aumento da oferta de informações disponíveis. O e-mail pode ser uma ferramenta maravilhosa de seleção de amostral, mas é utilizado em inúmeras situações. Muitos provedores, buscando proteção contra marqueteiros e pessoas inescrupulosas, limitam o tamanho da caixa postal e utilizam spam, impedindo que várias mensagens sejam recebidas pelo usuário (SMITH, 1997). Muitas mensagens que os pesquisadores enviam ao respondente podem não chegar ao destino previsto. Mesmo se chegarem, o respondente pode se perder em meio a tantas informações ou não abrilas por temer contágio de vírus, desinteresse ou falta de tempo.

Procurando minimizar o problema, algumas estratégias são recomendadas para gerar interesse nos respondentes, observando-se o impacto cultural específico da população. $O$ uso de prêmios e sorteios de brindes como incentivos tem ocorrido como forma de convencer o entrevistado a preencher as respostas. Outra forma produtiva é quando o pesquisador envia os comunicados e questionários da pesquisa, através de parceria com uma instituição de confiança do respondente. Ou seja, assim como a web possibilita maior incidência de respondentes, aumenta a proporção de não respondentes (3). Novos esforços no planejamento da pesquisa são envidados no sentido de obrigar o respondente a terminar a pesquisa, mas ele pode desistir por algum motivo. 
Apesar de os erros de mensuração (4) serem os mesmos das pesquisas tradicionais, Dillman e Bowker (2001); Alsnih (2005) e Couper (2001) pontuam a ocorrência de algumas dificuldades de natureza técnica nas investigações na web: indisponibilidade do sistema, interrupções de navegação, alteração do layout dos questionários provocada pelo tipo de equipamento do usuário (que prejudica a qualidade e padronização da apresentação), eventuais lentidões para conectar e autenticar no sistema e outros vieses. Tais problemas levam especialistas a defenderem o uso de padrões de protocolo, sendo HTML ou XML o mais conhecido. Pesquisadores buscam apoio em recursos técnicos para minimizar o efeito de interrupções, como a manutenção full time de vários servidores ligados. O pré-teste dos questionários estende-se, hoje, ao teste de conectividade e de outros recursos técnicos que interferem na coleta de dados.

\subsection{As Linhas Investigativas sobre Surveys}

As mudanças de cenário e de tecnologia despertam novos interesses nos estudiosos. Algumas sugestões de classificação de pesquisas surgiram. Couper (2001), Dillman e Bowker (2001) agruparam os trabalhos dos investigadores em três dimensões: pesquisas totalmente desenvolvidas na web (1); acesso restrito ou universal (2) e formas de contato e recrutamento (3). A primeira dimensão tenta distinguir pesquisas exclusivamente feitas na web e outras que combinam métodos, buscando comparar resultados.

A segunda dimensão refere-se à cautela no estudo da população e suas implicações no plano amostral. Em populações restritas, como no caso de empregados de uma instituição que respondem a uma pesquisa sobre clima organizacional, é possível controlar a amostra e eliminar etapas como identificação do respondente. Já em pesquisas de universo amplo, compostas de voluntários, não há controle e os resultados não são passíveis de generalização.

A terceira dimensão foca as formas de contato e comunicação com os respondentes, visando descobrir como eles podem ser localizados e suas implicações. Persiste a preocupação em se evitar a ambiguidade de comunicação em todas as etapas da investigação. Nesse sentido, alguns cuidados permanecem prioritários para os pesquisadores. A objetividade na correta definição do problema é a primeira difícil tarefa a cumprir. Muitas vezes, mesmo em pesquisas quantitativas, é necessária uma ou mais etapas de exploração qualitativa para clarear a 
problemática (Informação verbal) ${ }^{7}$, sobretudo, na elaboração dos questionários e roteiros de entrevista para coleta de dados. O cuidado com a comunicação objetiva e clara deve, ainda, permear a apresentação dos resultados.

Acrescentaríamos outras três dimensões, presentes em inúmeros artigos: (4) o formato, que é alvo de várias sugestões (formas de elaboração de questionários, layouts, recursos visuais e outros), (5) pesquisas sobre o comportamento do usuário, que tem despertado interesse acadêmico, pois o pesquisador precisa aprimorar sua compreensão sobre o comportamento humano, uma vez que o sucesso da pesquisa depende do interesse e disponibilidade do respondente e (6) do planejamento dos recursos disponíveis, envolvendo considerável arsenal tecnológico. Continua central no desenvolvimento das pesquisas a busca constante pela praticidade e redução de custos e prazos. Em todos os tempos, essas questões foram consideradas importantes, pois qualquer trabalho de investigação precisa ser colocado em prática, com início, meio e fim.

\section{O SURVEY}

Visando preencher as lacunas existentes, a pesquisa coletou dados sobre o uso do Portal de Periódicos da Capes, por docentes em 17 universidades federais brasileiras e em número abrangente de áreas e subáreas do conhecimento. $\mathrm{O}$ estudo teve por objetivos (1) caracterizar os usuários do Portal, incluindo seu domínio e uso de outros recursos informacionais; (2) analisar a extensão e natureza do uso e satisfação; (3) estudar o comportamento dos usuários na busca de informações; (4) analisar os problemas e dificuldades de uso do Portal de Periódicos da Capes, (5) analisar as razões para seu uso ou não uso; e (6) comparar a utilização do portal e o comportamento de busca do usuário entre as diferentes áreas de conhecimento, disciplinas e instituições pesquisadas. Os objetivos foram descritivos e também exploratórios já que são esperados novos questionamentos gerados pela análise dos dados. A metodologia foi principalmente quantitativa, com a coleta de alguns dados qualitativos. Estes foram levantados através de um websurvey que utilizou um conjunto de questionários como instrumento de pesquisa. A escolha do método foi motivada principalmente pela dispersão do público-alvo e

\footnotetext{
${ }^{7}$ Informação fornecida por Francisco Meira, doutor em Ciências Política/UFMG e diretor do Instituto Vox Populli em 2009.
} 
pelo tamanho da população. Além disso, a população específica estudada, com alto grau de afinidade e acesso à internet, permitia que o plano amostral fosse significativo, como recomendado pela literatura.

O primeiro questionário levantou o perfil do respondente e continha 16 perguntas sobre (a) dados demográficos, tais como idade, instituição, tempo de docência, horas dedicadas à pesquisa e outras; e (b) Interação com o meio eletrônico com perguntas sobre o uso e a familiaridade com instrumentos de informática, fontes eletrônicas e redes de informação, habilidades e atitudes. A última pergunta indagava se o respondente utilizava ou não o Portal e o direcionava para a próxima etapa de acordo com a resposta. Os não usuários do Portal recebiam um questionário diferenciado, com 10 perguntas sobre problemas, dificuldades, uso de outros meios eletrônicos, entre outras. Já aqueles que respondiam que utilizavam o Portal recebiam um segundo questionário denominado Uso do Portal Capes, mais longo, contendo 30 perguntas sobre o comportamento do usuário na busca de informação, estratégias de busca, recursos utilizados, propósitos do uso do Portal, impacto nas suas atividades, entre outras. O questionário não permitia o envio a não ser que todas as perguntas estivessem respondidas.

Para gerar interesse pela pesquisa e confiança no respondente, uma cartaconvite foi cuidadosamente elaborada para ser objetiva e ao mesmo tempo informar dados como o tempo necessário para preencher o questionário e contatos, caso 0 docente desejasse confirmar a fidedignidade do convite. A carta assegurava o sigilo dos dados e enfatizava a importância do preenchimento do questionário, mesmo que o respondente não utilizasse o Portal. O convite era personalizado com o nome do respondente automaticamente retirado dos bancos de dados.

Após algumas tentativas infrutíferas de obtenção de listas de docentes e seus endereços de e-mails diretamente das universidades e de seus departamentos, optou-se, apesar do risco maior de erros de cadastro, por levantar-se a lista nomes e de e-mails dos respondentes mediante pesquisa na Internet, nos sites das universidades e nos Currículos do Sistema Lattes. Levantaram-se desta forma os dados de 14.763 docentes de 17 universidades federais brasileiras.

Para o envio, observou-se o calendário das universidades federais, considerando os períodos de férias letivas e as greves ocorridas na ocasião em que 
se deu a pesquisa. Para aqueles que não responderam à chamada inicial, foram enviados dois e-mails de cobrança com um intervalo de 30 dias entre eles.

Durante a fase de recebimento de respostas, os e-mails enviados pelos respondentes que apresentavam dúvidas, sugestões, reclamações ou indicavam erros no sistema foram acompanhados diariamente e respondidos pessoalmente, embora, após identificação de alguns padrões nas mensagens pela coordenadora do projeto, tenham sido elaboradas cartas-resposta padronizadas de acordo com as situações. Os padrões adotados obedeceram à lista:

1. Pede confirmação de veracidade da pesquisa;

2. Pede maiores explicações sobre a pesquisa;

3. Pede para receber questionário em outro formato ou como documento anexo;

4. Pede confirmação sobre adequação ao perfil da pesquisa e se pode participar,

5. Informa que vai responder posteriormente por variados motivos;

6. Informa que não vai responder por variados motivos;

7. Informa que já respondeu;

8. Informa que o link não funciona;

9. Informa problemas técnicos em relação ao questionário;

10. Informa erro no seu nome e pede alteração;

11. Informa que não se adequa ao perfil da pesquisa;

12. Informa que respondeu mas verificou-se que falta resposta a um questionários;

13. Informa que respondeu e verificou-se que consta resposta na base de dados;

14. Informa problema de saúde;

15. Reclama da cobrança;

16. Acha que a origem da pesquisa é a CAPES;

17. Agradecimento;

18. Oferece feedback.

Durante o período de recebimento das mensagens, frequentes reuniões da equipe fizeram-se necessárias, para decisões sobre providências a tomar com relação a cada e-mail. A cada usuário eram enviadas respostas personalizadas e 
adaptadas à situação específica. Além do envio das respostas, foi elaborada uma tabela de providências a tomar, quando a mensagem assim o exigia. Por exemplo, no caso em que o usuário informava que respondera, era verificado que realmente constava resposta na base de dados, além do envio da carta, o respondente deveria ser excluído da base de envio de cobranças. Em relação aos erros técnicos reportados nas mensagens, cada um era discutido com o especialista em informática em reuniões semanais em que se definiam as providências corretivas e como deveria ser a resposta ao usuário.

Foram recebidos $564^{8}$ e-mails que, foram respondidos, exceto nos casos em que houve perda por problema técnico. Todas as mensagens foram automaticamente armazenadas para posterior análise.

\subsection{As Mensagens Recebidas}

Para comparar as preocupações identificadas na revisão de literatura com os resultados obtidos na pesquisa com os usuários do Portal Capes, foram analisados os comentários registrados em forma de questão aberta por pessoas que se manifestaram de alguma forma. Inicialmente, as 564 mensagens recebidas de 531 respondentes foram reorganizadas e aglutinadas em 531 comentários $^{9}$. A seguir, dividimos os comentários em algumas categorias, conforme TAB.1. Um mesmo comentário pode ter sido enquadrado em mais de uma categoria.

Ao receberem a carta de cobrança, 18 comentários agradeceram ou elogiaram a iniciativa da pesquisa. Alguns destes comentários afirmavam que já haviam preenchido e enviado o questionário. Houve, também, quem afirmasse não ter recebido nada anteriormente.

Dos comentários, 46 pediam para que os cadastros fossem atualizados, pois os dados haviam alterado. Tais pedidos foram atendidos pela equipe do projeto. Também ao receberem a carta de cobrança, outros 27 comentários eram de docentes que se manifestaram confusos, pois já tinham respondido o questionário. De fato, verificou-se que 25 deles foram indevidamente cobrados.

80 número inclui mensagens trocadas com o mesmo usuário em várias iterações de uma mesma conversa.

${ }^{9}$ Cabe observar que foi uma coincidência o número de comentários ser igual ao número de pessoas (531) que enviaram mensagens, visto que tal coincidência pode ocasionar confusão. 
Foram recebidos 14 comentários com críticas e sugestões, dirigidas à elaboração do questionário (conteúdo, estrutura, categorias), às falhas de comunicação e a Capes.

Tabela 1 - Comentários de respondentes com problemas

\begin{tabular}{|c|l|c|}
\hline & \multicolumn{1}{|c|}{ Categoria } & Quantidade \\
\hline 1 & Agradecimento/elogio & 18 \\
\hline 2 & Atualizar cadastro & 46 \\
\hline 3 & Confuso das etapas & 27 \\
\hline 4 & Critica & 14 \\
\hline 5 & Desconfiança de vírus & 18 \\
\hline 6 & Dúvida sobre cadastro, & 34 \\
\hline 7 & Erro de abertura ou acesso & 40 \\
\hline 8 & Erro amostral & 46 \\
\hline 9 & Erro de envio & 62 \\
\hline 10 & Erro de preenchimento & 08 \\
\hline 11 & Erro de recebimento & 05 \\
\hline 12 & Mail despercebido & 36 \\
\hline 13 & Não recebeu & 05 \\
\hline 14 & Promessa & 45 \\
\hline 15 & Recusa & 57 \\
\hline 16 & Respondida & 166 \\
\hline 17 & Solicita mais informações & 599 \\
\hline & TOTAL & \\
\hline
\end{tabular}

Base: 531 mensagens com múltiplos comentários.

Fonte: Cendón (2010).

18 comentários registraram que se sentiram inseguros ao receberem o questionário, por temor de vírus. Alguns solicitaram mais informações, confirmação de veracidade ou de recebimento pelo pesquisador.

34 comentários mostram dúvida sobre enquadramento do docente na população investigada. De fato, 23 respondentes não se adequavam (por exemplo, por terem mudado de emprego) e foram excluídos da amostra após averiguação do comentário pela equipe de pesquisa.

Os erros de abertura do questionário foram apontados por 40 comentários, sendo 36 casos atribuídos a problemas técnicos e 04 casos a problema de navegação no questionário.

Foram identificados 46 casos de erro cadastral, todos excluídos da pesquisa, como perfil inadequado, aposentados e até um falecido (cabe lembrar que os dados 
cadastrais da pesquisa foram coletados diretamente nos sites das universidades, que poderiam estar desatualizados).

Entre as 62 ocorrências registradas como 'de erros de envio', 06 foram provocadas por erro de endereçamento, casos em que os cadastros foram corrigidos; 29 comentários registram problemas no envio do questionário. 20 comentários mostram problemas técnicos de comunicação, como conexão com o link ou com o servidor. Três comentários são de pessoas que assumiram ter pouco conhecimento de informática e pediram ajuda. Quatro comentários mostram críticas ou reclamações.

Os erros específicos de preenchimento foram registrados por oito comentários, sendo quatro casos atribuídos às falhas de navegação do questionário, dificuldades com hardware (2), falta de tempo e pedido de ajuda.

Em cinco comentários, respondentes alegaram não terem recebido o questionário, possivelmente por problemas tecnológicos.

Foram identificadas 36 comentários dos quais 20 são de respondentes que talvez não perceberam os primeiros emails enviados por problemas de spam, falta de tempo, férias, doença, atenção e outros motivos. 16 comentários são de pessoas pediram reenvio ou encontraram o questionário entre os arquivos, alguns alegando que o script poderia ter passado despercebido em meio ao grande número de mensagens que recebem diariamente.

Cinco comentários são de pessoas que afirmaram não ter percebido o questionário (talvez tenha sido bloqueados pelo sistema, por exemplo) e solicitaram confirmação de veracidade.

45 comentários são de pessoas que confirmaram o recebimento e prometeram responder. Várias pediram desculpas, outras alegaram falta de tempo, férias, saúde e outros motivos.

57 comentários são de pessoas que se recusaram a responder, por motivos diversos, dentre outros: por não se julgarem pertencentes à amostra (44 comentários) e por motivos pessoais (desinteresse, aposentadoria, falta de tempo, férias, saúde, viagem, não concordar com questões desnecessárias do questionário ou se achar muito qualificado - 13 comentários).

Finalmente 166 comentários são de indivíduos que afirmaram ter respondido à pesquisa. 78 comentários são de pessoas que forneceram algum feedback e 88 comentários descreveram problemas diversos de comunicação com o sistema. No 
conjunto, 16 comentários são de pessoas que pediram mais informações e 10 comentários pediam confirmação sobre a veracidade do projeto. Os números são significativamente baixos e se comparados ao total de respondentes, leva a inferir que o questionário conseguiu a clareza, objetividade e simplicidade recomendadas, além de revelar que o planejamento e o acompanhamento da pesquisa foram bem conduzidos.

Partindo da TAB 1, fizemos nova categorização, chegando à TAB.2. Com as novas categorias, chegaríamos à TAB.3 e Gráfico 1.

A definição final de categorias baseou-se nas análises dos comentários, quando se observou a que categoria o comentário predominantemente se adequava, e nas observações identificadas na revisão de literatura. Assim, foi eleita a tipologia como categorias: cadastro, problemas de comunicação, comunicação de problemas de ordem técnica, questionário e feedback.

\section{DISCUSSÃO}

Os resultados esclarecem que algumas preocupações encontradas nos artigos de especialistas que estudam a websurvey são pertinentes. Os comentários analisados corroboraram para justificar alguns desafios que os pesquisadores enfrentam, dentre eles: planejar estrutura de suporte tecnológica eficiente; manter cadastro atualizado do público alvo, do qual se possa extrair amostra representativa, e zelar continuamente para a comunicação simples e direta, que possibilite o perfeito entendimento do respondente.

A delicadeza das questões tecnológicas revela-se nos $24,9 \%$ dos comentários que se referiram à comunicação de problemas técnicos na abertura e ao envio dos questionários e reclamações quanto à dupla recepção de questionários. Por isto, o planejamento da pesquisa deve contemplar a gestão de ruídos provocados pelas implicações tecnológicas na gestão do processo comunicativo. Manter o servidor ligado, testar o link diariamente, são algumas das providências possíveis. Tal problema tende a diminuir, na medida em que o envio de questionários for substituído pelo preenchimento em hotsite, como defendem alguns especialistas. Neste modelo, através do link tipo "fale conosco", é possível a interação mais personalizada e ágil entre pesquisador e respondente. Recomenda-se, também, o uso de softwares comerciais para o desenvolvimento de surveys, menos propensos 
a problemas como os que ocorreram com a corrente pesquisa, que usou um software customizado para as necessidades da pesquisa, mas que foi responsável por muitas das dificuldades enfrentadas. Outra particularidade tecnológica do questionário é que ele emitia mensagem de erro de envio se não preenchido completamente, exigindo que o respondente o finalizasse. Esta foi uma opção de design do questionário que ocasionou irritação e reclamações dos respondentes, embora garantisse respostas completas. Todas estas decisões têm impacto na reação dos respondentes e devem ser consideradas no planejamento da pesquisa.

Também na categoria Comunicação, alguns comentários foram ocasionados por um problema ocorrido com o servidor que ocasionou o reenvio automático de cartas-convite e provocou mensagens com reclamações e outras informando em os docentes informavam que já haviam respondido. $4,5 \%$ do total de mensagens foram motivadas for este problema técnico. Já $2,7 \%$ do total das mensagens foram pedidos de pessoas que gostariam de saber mais sobre a pesquisa além dos que estava informado na carta convite. A carta convite fornecia informações gerais sobre a pesquisa e fornecia links, e-mails e números de telefones estimulando o contato dos que desejassem maiores informações. É interessante observar que muitos foram os telefonemas recebidos de vários estados do Brasil de docentes que receberam a carta convite.

Ainda dentro das mensagens da categoria Comunicação, metade das mensagens (30\% no total de mensagens) ofereceram algum feedback para os pesquisadores, seja para elogios ou agradecimentos ou críticas, bem como informações dos docentes sobre quando poderiam enviar o questionário preenchido, comunicando erros de envio ou preenchimento ou outras comunicações. Tais retornos demonstram interesse pela pesquisa por parte dos docentes e parecem indicar que houve competência na gestão do processo informacional com os pesquisados. 
Consuelo Chaves Joncew; Beatriz Valadares Cendon; Nádia Ameno

Websurveys como método de pesquisa

Tabela 2 - Nova categorização dos comentários

\begin{tabular}{|l|l|r|}
\hline Categoria anterior & Nova Categoria & Quantidade \\
\hline Agradecimento/elogio & Feedback & 18 \\
\hline Atualizar cadastro & Cadastro & 46 \\
\hline Confuso das etapas & Comunicação & 27 \\
\hline Critica & Feedback & 14 \\
\hline Desconfiança de vírus & Comportamento & 18 \\
\hline Dúvida sobre cadastro & Cadastro & 34 \\
\hline Erro de abertura ou acesso & Comunicação técnica & 36 \\
\hline Erro de abertura ou acesso & Questionário & 4 \\
\hline Erro amostral & Cadastro & 46 \\
\hline Erro de envio & Cadastro & 06 \\
\hline Erro de envio & Questionário & 29 \\
\hline Erro de envio & Comportamento & 04 \\
\hline Erro de envio & Feedback & 03 \\
\hline Erro de envio & Comunicação técnica & 20 \\
\hline Erro de preenchimento & Questionário & 04 \\
\hline Erro de preenchimento & Feedback & 02 \\
\hline Erro de preenchimento & Comportamento & 02 \\
\hline Erro de recebimento & Comunicação técnica & 05 \\
\hline Mail despercebido & Comportamento, & 20 \\
\hline Mail despercebido & Feedback & 16 \\
\hline Não recebeu & Feedback & 05 \\
\hline Promessa & Feedback & 45 \\
\hline Recusa & Cadastro & 44 \\
\hline Recusa & Comportamento & 13 \\
\hline Respondida & Comunicação técnica & 58 \\
\hline Respondida & Feedback & \\
\hline Solicita mais informações & Comunicação & \\
\hline & Total & \\
\hline
\end{tabular}

Base: 531 mensagens com múltiplos comentários Fonte: Cendón (2010).

Tabela 3 - Síntese Dos Comentários

\begin{tabular}{l|r|r|}
\hline Nova Categoria & Quantidade & $\%$ \\
\hline Cadastro & 132 & 22 \\
\hline Subtotal cadastro & $\mathbf{1 3 2}$ & $\mathbf{2 2}$ \\
\hline Comportamento & 44 & 7,4 \\
\hline Comportamento recusa & 13 & 2,2 \\
\hline Subtotal comportamento & $\mathbf{5 7}$ & $\mathbf{9 , 6}$ \\
\hline Comunicação problemas & 43 & 7,2 \\
\hline Comunicação/problemas técnicos & 149 & 24,9 \\
\hline Feedback & 181 & 30,2 \\
\hline Subtotal comunicação & $\mathbf{3 7 3}$ & $\mathbf{6 2 , 3}$ \\
\hline Questionário & 37 & 6,2 \\
\hline Subtotal questionário & $\mathbf{3 7}$ & $\mathbf{6 , 2}$ \\
\hline Total & $\mathbf{5 9 9}$ & $\mathbf{1 0 0 , 0 0}$ \\
\hline Base: & & \\
\hline
\end{tabular}

Base: 531 mensagens com múltiplos comentários Fonte: Cendón (2010).

Inf. Inf., Londrina, v. 19, n. 3, p. 192 - 218, set./dez. 2014. http:www.uel.br/revistas/informacao/ 


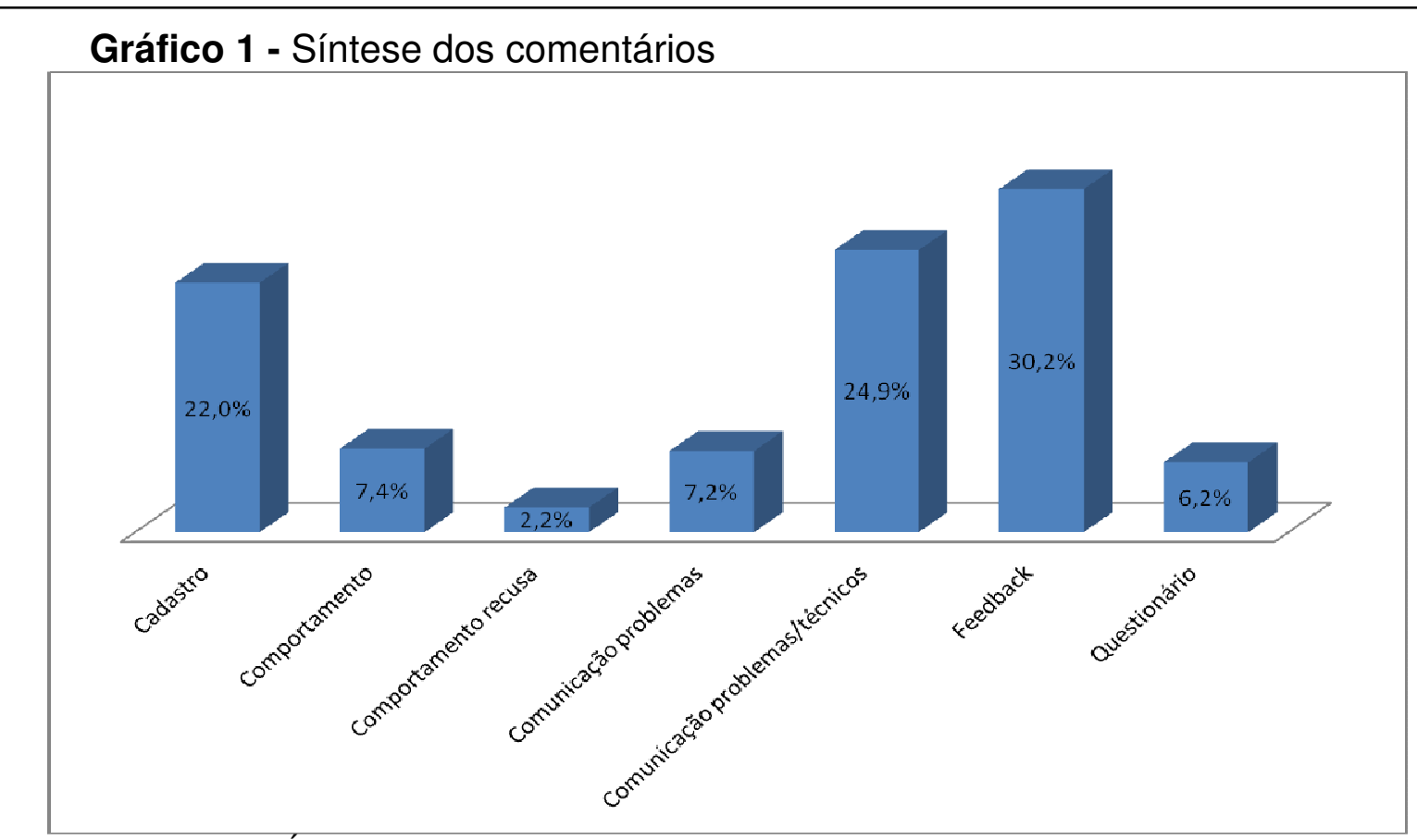

Fonte: CENDÓN (2010).

Problemas com cadastro representaram $22 \%$ das ocorrências registradas nos comentários, demonstrando a importância do zelo no tratamento amostral. No caso da corrente pesquisa, é importante ressaltar que, na impossibilidade da obtenção dos dados cadastrais por outra via, estes foram obtidos diretamente nos sites dos departamentos, os quais poderiam estar incorretos.

Fatores de ordem comportamental merecem atenção e continuam fecundo campo de investigações, como: interação do usuário com o sistema, hábitos de leitura de e-mails, protocolos de bloqueios de spam, nível de confiança nos pesquisadores, desconfiança de vírus, falta de tempo para lidar com excesso de informações e outros. Variáveis de ordem comportamental representaram 9,6\% das observações contidas nos comentários dos respondentes.

Por fim o planejamento do questionário merece destaque. Apesar de apenas $6,2 \%$ dos comentários se referirem ao instrumento, ele está intrinsecamente ligado ao problema da comunicação técnica. Os dados colhidos demonstram que a elaboração do script é ponto crítico do processo da pesquisa. Por isto, seu desenho deve ser tarefa meticulosa, bastante estudada e testada. A preocupação com o layout e as formas de atrair o respondente deve ser considerada incessantemente, para evitar problemas de acesso, entendimento, navegação e envio das respostas. O baixo número de críticas ao questionário revelou competência da equipe que planejou a pesquisa sobre o uso do Portal Capes. 
Finalmente, gostaríamos de salientar que as categorias são variáveis interdependentes e influenciam o bom ou mau desempenho do desenvolvimento de uma pesquisa.

\section{CONCLUSÃO}

Temas relativos à websurvey merecem maior atenção da academia.

Vimos que o desenvolvimento e popularização da informática, ao lado do incremento da telefonia, impactaram consideravelmente o planejamento da pesquisa. A partir dos anos 90 , até então terreno exclusivo de especialistas no assunto, "pesquisas de mercado" começaram a ser empreendidas em inúmeros sítios da internet. No entanto, tais pesquisas, na verdade, referiam-se às enquetes, levantamentos simples de opinião sobre algo específico. Algumas instituições começaram a ensaiar passos de pesquisas, de forma amadorística, pedindo a técnicos de informática que elaborassem scripts ou questionários, sem o devido planejamento profissional que o trabalho requereria. Inúmeros bancos de dados disponíveis foram transformados em populações, das quais se retiravam amostras aleatórias para entrevistas. A informática permitiu a esses amadores a imediata tabulação das respostas elaboradas sem categorização planejada. Relatórios com gráficos sofisticados inundaram as salas dos gerentes. Tomadores de decisão ficavam deslumbrados com arsenal de dados, que nem sempre tinham relação lógica ou analítica entre eles. Tal quadro ampliou com a disseminação crescente da internet. Esta bizarra realidade, conhecida nas grandes organizações, constituiu um dos fatores que deixaram muitos acadêmicos e especialistas, num primeiro momento, desconfiados dos "novos profissionais" de pesquisa (DILLMAN; BOWKER, 2001; COUPER, 2001) atrasando o avanço científico sobre o tema.

Passada a febre da invasão de tecnólogos e amadores no universo do trabalho dos pesquisadores, considerando as relevantes contribuições da tecnologia na área, especialistas reconhecem a necessidade de aprofundarem seus estudos sobre o assunto, para proporcionar avanços qualitativos no trato metodológico. (DILLMAN et al. 2001). Hoje, acadêmicos e especialistas, aqueles que estruturam as pesquisas, escolhem as técnicas, coletam dados, tabulam e analisam aprimoram seus conhecimentos em informática e navegação na internet. Gunn (2002) e Smith (1997) destacam que o perfil do profissional de pesquisa mudou, já que exige a 
capacidade e facilidade de lidar com as novas tecnologias, sobretudo com a web. A elaboração de um questionário, que antes exigia habilidade de raciocínio de comunicação, hoje requer, também, conhecimento sobre design, familiaridade com protocolos da internet e outros. Fatos curiosos têm ocorrido no universo acadêmico. Disciplinas como estatística e sobre uso de softwares ganharam destaque em vários cursos de ciências sociais aplicadas, tradicional reduto de profissionais de instituto de pesquisa.

Apesar das mudanças de cenário, sobretudo no que diz respeito às tecnologias de comunicação, três desafios básicos e conceituais permanecem. São eles: o planejamento e desenho da pesquisa, a preocupação com a eficácia da comunicação entre os atores da pesquisa e a contínua busca pela otimização de recursos. A partir desses três desafios-planejamento, comunicação e redução de custo-, discorreremos sobre mais alguns impactos trazidos pelas novas tecnologias de informação, sobretudo com as pesquisas feitas pela internet.

O armazenamento em banco de dados permite a definição de populações homogêneas, algumas delas acessíveis por endereço eletrônico. Segundo especialistas, nos casos em que a população é bem definida e uniforme, o uso do websurvey torna-se alternativa metodológica confiável. Para isto, deve-se certificar que todos os indivíduos têm acesso à rede pesquisada. $O$ trabalho desenvolvido com os usuários do portal Capes enquadra-se nesta categoria. A definição do plano amostral recebeu grandes contribuições da informática, devido à disponibilização de softwares estatísticos interativos e amigáveis, dispensando o uso de fórmulas complexas.

Devemos lembrar que o websurvey não é uma alternativa sempre generalizável, porque estatísticas mostram que o acesso à internet não é homogêneo em todo o mundo. Quando não há uniformidade entre os indivíduos da população, ele é contra indicado, pois desfavorece a estratificação de amostras, comprometendo sua representatividade diante o universo.

Definida a metodologia e o plano amostral, parte-se para a elaboração e escolha dos instrumentos e técnicas de coleta de dados. No caso de uma pesquisa quantitativa, o questionário tende a ser digitado em sofisticados programas computadorizados e disponibilizado em hotsite, com o envio de um link do sítio para ser acessado e respondido. 
Como o entrevistador não está mais presente (SMITH, 1997), o desenho do instrumento de coleta de dados requer bastante cuidado, para que se consiga minimizar dois dos principais obstáculos ao sucesso de uma investigação: a ambiguidade de comunicação e a geração de interesse no respondente. Embora a tecnologia tenha colaborado para a comodidade de eliminar o cadastramento de identificação, a elaboração do instrumento de coleta de dados tornou-se tarefa demorada, requerendo várias discussões entre os especialistas em pesquisa, especialistas em informática, especialistas em comunicação e em psicologia. Muitos profissionais da área defendem a padronização dos protocolos de envios de dados, visando a evitar ruídos de comunicação.

A metodologia do websurvey colocou o entrevistador nos bastidores e evidenciou o instrumento de coleta de dados: o questionário. Sai de cena a subjetividade do entrevistador e entra em cena a subjetividade do respondente. Por isto, a tentativa de eliminar ruídos de comunicação, a preparação dos instrumentos e questionários requer superação de novos desafios. A explicitação do objetivo de cada pergunta é essencial para diminuir erros. Acadêmicos estudam as melhores técnicas para evitar redundâncias ou redundâncias necessárias para evitar ambiguidade. O foco é a compreensão do raciocínio e comportamento humano.

Nesse sentido, o contexto do respondente passou a preocupar os planejadores de pesquisa, pois se transformou em variável relevante. Dúvidas surgem: Como seria o ambiente do respondente? Teriam eles os mesmos recursos de interatividade, linguagem, velocidade de acesso? Acessariam o formulário ou seus computadores travariam a abertura do programa? Teriam acessado o link do sítio da pesquisa ou é preciso validação? Que equipamento tem? Qual o seu tipo de protocolo de envio e recebimento? Estaria o respondente realmente disponível para se concentrar nas respostas ou ele poderia estar fazendo outra atividade ao mesmo tempo? Teriam todos os respondentes o mesmo nível de conhecimento de informática?

As observações dos respondentes de nossa pesquisa comprovaram que as preocupações citadas procedem. $\mathrm{O}$ medo da existência de vírus foi registrado nas respostas. Alguns entrevistados posicionaram-se sobre incompatibilidade de hardware, erros de validação, erro de acesso a link do questionário. Outras ficaram em dúvida se pertenceriam ao público alvo. Lembra Smith (1997) que o tamanho e a 
extensão demográfica da população da internet crescem, mas a habilidade em lidar com o a crescente oferta de informação não.

Como o excesso de recebimento de informação poderia interferir na pesquisa?

O campo da tabulação recebeu grande colaboração do desenvolvimento tecnológico. Ela pode, agora, ser quase simultânea, diminuindo consideravelmente o tempo e reduzindo custos, além de permitir a elaboração de elegantes relatórios de apresentação de dados. Comparada aos métodos tradicionais de pesquisa, a websurvey permite comparações criativas devido às fáceis extrações de queries dos dados armazenados nos bancos de dados, cujas informações são facilmente recuperáveis. Com isto uma pesquisa de grande extensão permite a derivação de inúmeros artigos em abordagens diferenciadas (BATINIC; BOSNAJK, 2002).

Através das observações feitas em questões abertas, nossa pesquisa sinalizou diferenças de comportamento dos respondentes. Seria prematuro creditar tal fato à diversidade do contexto cultural ou econômico. Porém, recomendaríamos aprofundamento no assunto. Por fim, devemos salientar que o sucesso da pesquisa continua a decorrer da delimitação mais exata possível do problema, do planejamento cuidadoso, da coleta primorosa de dados e da análise competente do entrevistador. E permanece a continua a dúvida: o que fazer com os dados?

Enfim, podemos concluir que a metodologia da websurvey ainda se encontra na infância, com vários desafios a serem assumidos, em investigações instigantes.

\section{REFERÊNCIAS}

ALSNIH, Rahaf. Characteristics of Web-based surveys and applications in travel research. In: INTERNATIONAL CONFERENCE ON SURVEY METHODS IN TRANSPORT - ISCTSC, 2005, Costa Rica. CD-Rom.

ARENTZE, Theo; HOFMAN, Frank; TIMMERMANS, Harry. Predicting Multi-Faceted Activity-Travel Adjustment Strategies in Response to Possible Congestion Pricing Scenarios Using an Internet-Based Stated Adaptation Experiment. Transport

Policy, The Hague, v.11, n. 1, p. 31-41, 2004.

BABBIE, Earl. Métodos de pesquisa de survey. Belo Horizonte: UFMG, 2005. 
BATINIC, Bernad; BOSNJAK, Michael. Understanding the willingness to participate in online-surveys. In: BATINIC, Bernad; REIPS, Ulf-Dietrich; BOSNJAK, Michael (Eds.). Online social sciences. Seattle, WA: Hogrefe \& Huber, 2002.

BONNEL, Patrick; LE NIR, Michael. The quality of survey data: telephone versus face-to-face interviews. Transportation, Amsterdam, v. 25, n.2, p.147-167, 1998.

BOSNJAK, Michael; TUTEN, Tracy. Classifying Response Behaviors in Web-based Surveys. Journal of Computer-Mediated Communication, v. 6, n. 3, 2001.

BRADLEY, Nigel. Sampling for internet surveys; an examination of respondent selection for internet research. International Journal of Market Research, v. 41, n.4, p. 441-452, 1999.

BURGESS, Thomas F. A General introduction to the design of questionnaires for survey research. 2001. Disponível em:<http://iss.leeds.ac.uk/info/312/surveys/ 217/guide_to_the_design_of_questionnaires. Acesso em: 10 fev. 2014.

CENDON, Beatriz Valadares et al. Utilização de Web Surveys para Estudos de Uso. Informação \& Sociedade: Estudos, João Pessoa, v. 20, n. 3, 2010.

CHAIKEN, Shelly. Heuristic versus systematic information processing and the use of source versus message cues in persuasion. Journal of Personality and Social Psychology, Washington, v.39, p.752-766, 1980.

CHAIKEN, Shelly. The heuristic model of persuasion'. In: ZANNA, Mark P.; OLSEN, James; HERMAN, C. Peter M. P. (Ed.). Social influence: The Ontario symposium. Hillsdale, NJ: Erlbaum, 1987. v. 5.

COUPER, Mick P. Web Surveys: the Questionnaire Design Challenge. In: ANNUAL MEETING OF THE AMERICAN STATISTICAL ASSOCIATION, 53., 2001.

Proceedings... 2001.

DILLMAN, Don A.; TORTORA, Robert D., BOWKER, Dennis. Principles for Constructing Web Surveys. Washington: Pullman, 1998. (SESRC Technical Report 98-50). Disponível em:<http://134.121.51.35/dillman/papers/1998/ Principlesfor ConstructingWebSurveys.pdf>. Acesso em: 10 fev. 2014.

DILLMAN, Don A.; BOWKER, Dennis. Web Questionnaire Challenge to Survey Methodologists. In: REIPS, Ulf-Dietrich; BOSNJAK, Michael. (Ed.). Dimensions of Internet Science. Pabst Science Publishers: Lengerich, p. 159-178, 2001.

DILLMAN, Don A.; REDLINE, Cleo D.; CARLEY-BAXTER, Lisa R. Influence of type of question on skip pattern compliance in self-administered questionnaires.

Proceedings of the American Statistical Association, Survey Research Methods Section, 1999.

DILLMAN, Don A. et al. Response Rate and Measurement Differences in Mixed Mode Surveys Using Mail, Telephone, Interactive Voice Response and the Internet. 2001. Disponível em:<http://www.sesrc.wsu.edu/dillman/papers/ 2001/responserateandmeasurement.pdf>. Acesso em: 10 fev. 2014. 
GROVES, Robert M.; CIALDINI, Robert B.; COUPER, Mick P. Understanding the decision to participate in a survey. Public Opinion Quarterly, Chicago, v.56, p.475495, 1992.

GUNN, Holly. Web-based surveys: Changing the survey process. First Monday, Chicago, v. 7, n. 12, 2002.

HANSEN, Christian K. Web site survey. Quality and Reliability Engineering International, Chichester, v.6, n.2, p. 334-335, 2000.

IRAGUEN, P.; ORTUZAR, Juan De Dios. Willingness-to-pay for reducing fatal accidents risk in urban areas: an internet-based web page stated preference survey. Accident Analysis and Prevention, Elmsford, v. 36, n. 4, p. 513-524, 2004.

PETTY, Richard E.; CACIOPPO, John T. Communication and Persuasion: Central and peripheral routes to attitude change. New York: Springer-Verlag, 1986.

PETTY, Richard E.; CACIOPPO, John T. The effects of involvement on response to argument quantity and quality. Journal of Personality and Social Psychology, Washington, v.46, p.69-81, 1984.

REDLINE, Cleo et al. Making Visible the Invisible: An Experiment with Skip Pattern Instructions on Paper Questionnaires. Proceedings of the ASA Section on Survey Research Methods. Alexandria, VA: American Statistical Association, 2001.

Disponível em:<http://www.census.gov/srd/papers/pdf/sm00-02.pdf>. Acesso em: 10 fev. 2014.

SCHAEFER, David R.; DILLMAN, Don A. Development of a standard e-mail methodology: Results of an experiment. Public Opinion Quarterly, Chicago, v.62, n.3, p.378-397, 1998.

SMITH, Christine B. Casting the net: Surveying an Internet population. Journal of Computer-Mediated Communication, v. 3, n. 1, 1997.

STOPHER, Peter R.; COLLINS, Andrews; BULLOCK, Philip. GPS survey and the internet. Sydney: Institute for Transport Studies, University of Sydney and Monash University, 2004.

ZANUTTO, Elaine. Web \& E-mail Surveys. 2001. Disponível em:<http://wwwstat.wharton. upenn.edu/ zanutto/Annenberg2001/docs/ websurveys01.pdf >. Acesso em: 6 nov. 2009.

Title

Websurveys as a research method

Abstract 
Introduction: The present article reports the analysis of 531 comments extracted from 564 messages received from respondents to a survey which collected data regarding the use of the CAPES Portal by faculty of Federal Brazilian universities.

Objective: The study seeks to bring more light about the challenges and difficulties of websurveys through the analysis of the messages received from the respondents, of the factors which motivate these messages, of the respondent's reactions to the websurvey and of the analysis of similar studies found in the literature.

Methodology: The methodology was mostly quantitative, with the collection of some qualitative data. The data came from messages sent by the users to the researchers and also from some open fields of the websurvey.

Results: The comments analyzed corroborated to justify some challenges which the researchers face, amongst them: planning efficient technological support structure, maintenance of updated information about the target audience, from which a representative sample can be extracted, and a continual watch to keep communication simple and direct, which allows perfect understanding of the respondent.

Conclusions: It was concluded that the methodology of the websurvey is still in its infancy with several challenges to be faced in instigating research.

Key-words: Survey. Digital libraries. Use study.

\section{Título}

Websurveys como un método de investigación

\section{Resumen}

Introducioón: El artículo comparte el análisis cualitativo de las observaciones registradas por 531 personas que utilizan el Portal de Periódicos CAPES, cubriendo 14.763 docentes de 17 universidades federales brasileñas. Se han recogido datos cualitativos en mensajes de los usuarios para los estudiosos y en cuestionarios.

Meta: Arrojar luz sobre los retos y las dificultades para realizar websurveys.

Resultados: Los comentarios analizados corroboran para justificar algunos de los desafíos que enfrentan los investigadores, como las estructuras de planificación de servicio técnico eficaz; mantener actualizada la audiencia, de la cual se pudiera extraer de una muestra representativa; y de forma continua para asegurar la comunicación simple y directa, lo que permite perfecta comprensión de la parte demandada.

Conclusión: Se concluye que la metodologia de websurvey se encuentra todavia en su infância, com muchos retos a superar.

Palabras- clave: Survey. Bibliotecas digitales diários. Estudios de usuário.

Recebido em: 06.03.204

Aceito em: 16.12.2014 